\title{
Syndromes of microcephaly, microphthalmia, cataracts, and joint contractures
}

\author{
ROBIN M WINTER*, DIAN DONNAI $\dagger$, AND MARTIN d'A CRAWFURD* \\ From * the Kennedy Galton Centre, Harperbury Hospital, Harper Lane, Radlett, Hertfordshire WD7 9HQ; \\ *the Division of Inherited Metabolic Diseases, Clinical Research Centre, Northwick Park Hospital, \\ Watford Road, Harrow, Middlesex HAI 3UJ; and †the Department of Medical Genetics, St Mary's \\ Hospital, Hathersage Road, Manchester M13 OJH
}

SUMmary Three infants are described, one with the Neu-Laxova syndrome and two with the cerebro-oculo-facio-skeletal (COFS) syndrome. The relationship between these two syndromes is discussed in the light of the present cases and others in published reports.

Pena and Shokeir ${ }^{1}$ described ten infants with a syndrome consisting of microcephaly, microphthalmia, cataracts, and joint contractures and in most cases characteristic facial appearance. They believed that autosomal recessive inheritance was involved in what they referred to as the cerebro-oculo-facioskeletal syndrome (COFS) syndrome. A follow-up of some of the original cases and details of several new ones, ${ }^{2}$ together with other reports ${ }^{3}{ }^{4}$ which probably describe the same syndrome under different names, firmly established the existence of the COFS syndrome. However, details of other cases ${ }^{5-8}$ have led Pena $e t a l^{2}$ to suggest that other similar syndromes exist within the "same phenotypic syndrome community".

Infants described by Neu et $a l^{9}$ and Laxova et al ${ }^{10}$ had microcephaly and joint contractures but were also characterised by oedema and bizarre facial features. Similar infants were described by Lazjuk et al $^{11}$ who drew attention to reports in the Czech literature, ${ }^{12}$ and following a review of all known cases they suggested that the constellation of signs be called the Neu-Laxova syndrome. However, the COFS syndrome, which may itself be heterogeneous, and the Neu-Laxova syndrome have sufficient features in common for some authors to consider them to be possibly part of the same entity. ${ }^{713} \mathrm{In}$ the absence of a specific biochemical or other marker it is impossible to resolve this diagnostic heterogeneity and in this report we describe three further cases, two of whom appear to conform most closely to the COFS group, and one of whom has features common to both the COFS and Neu-Laxova syndromes.

Rece.ved for publication 29 May 1980

\section{Case reports}

CASE 1

This was a term female infant born to a 23 -year-old Caucasian primigravida. There was no family history of similar abnormalities and no known parental consanguinity. Pregnancy was uneventful and there was no history of drug ingestion. Birthweight was $1.36 \mathrm{~kg}(<3 \mathrm{rd}$ centile) and the head circumference was $24 \mathrm{~cm}(<3 \mathrm{rd}$ centile). The forehead was sloping, the nasal bridge broad and prominent, and the eyes sunken and tightly closed

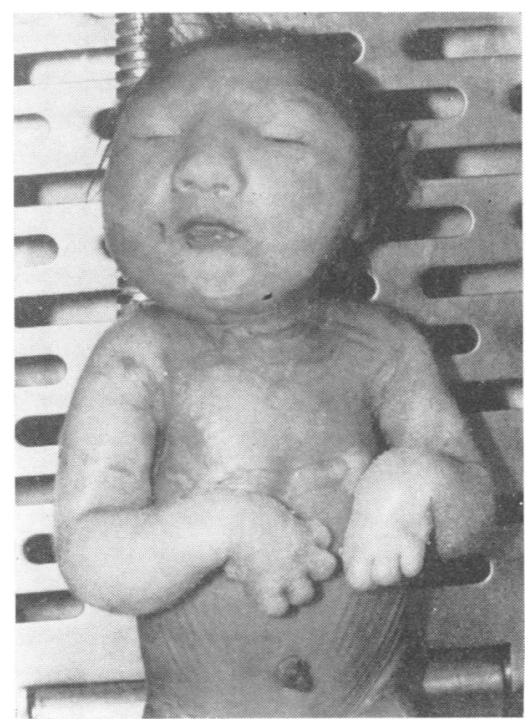

FIG 1 Case 1. 
with microphthalmia and cataracts (fig 1). There was micrognathia, with the upper lip overhanging the lower, and malformed ears with abnormal antihelices. The mouth and palate were normal. The neck was short and the chest broad, and there were flexion contractures of the elbows, wrists, fingers, hips, knees, and ankles with bilateral rocker-bottom feet. The skin of the trunk was yellow, shiny, cracked with peeling in places, and resembled the collodion skin of infants with congenital ichthyosis. The baby died at 3 hours of age. A necropsy examination was refused. Investigations for intrauterine infection were negative. The karyotype ( $\mathrm{G}$ banded) was $46, \mathrm{XX}$.

\section{CASE 2}

This was a female infant who was the product of a term normal delivery to a 23-year-old Asian Indian primigravida. Pregnancy was normal and there was no history of drug ingestion or viral infections. The parents were first cousins. Birthweight was $2.2 \mathrm{~kg}$ ( $<3$ rd centile), head circumference was $29.5 \mathrm{~cm}$ ( $<3$ rd centile), and length was $53 \mathrm{~cm}$ (50th centile). At birth she was noted to have microcephaly, cataracts, and multiple joint contractures. On examination at 4 months of age her weight was $3.6 \mathrm{~kg}(<3 \mathrm{rd}$ centile), length $60 \mathrm{~cm}$ (25th centile), and head circumference $35 \cdot 1 \mathrm{~cm} \quad(<3 \mathrm{rd}$ centile). She was microcephalic with a sloping forehead, prominent root of the nose, bilateral cataracts, mild hypotelorism, and convergent strabismus (fig 2). The neck was short. There was marked scoliosis of the spine with a mongolian blue spot to the left of the sacrum and a large $(1.5 \mathrm{~cm})$ pilonidal sinus. A small umbilical hernia was present, but otherwise the abdomen and external genitalia were normal. Tone of the limbs was much increased and the tendon reflexes were very brisk. There were multiple flexion contractures of the elbow, wrists, fingers, hip, knees, and ankles. The skin of the soles of the feet manifested some longitudinal folding although there was no rocker-bottom deformity. The skin was normal. Investigations for rubella, toxoplasma, and cytomegalovirus infection were negative. Urine analysis for amino-acids and reducing substances was negative. Chromosome studies ( $G$ banded) showed a $46, \mathrm{XX}$ karyotype. The patient failed to thrive and had severe feeding difficulties. Development was severely retarded. She died at the age of 5 years, probably of bronchopneumonia. Her weight at death was $8 \mathrm{~kg}(<3 \mathrm{rd}$ centile). Necropsy examination was not carried out.

\section{CASE 3}

This was a female infant, the second child born to healthy non-consanguineous Caucasian parents. The first child, at the age of 8 years, is physically and developmentally normal and there is no relevant family history. There were no illnesses in the second pregnancy and no drugs, apart from iron tablets, were taken. Delivery was by forceps and the birthweight of the infant was $3.28 \mathrm{~kg}$ ( 25 th centile). The early neonatal period was uneventful but at the age of 4 months her weight was $5.67 \mathrm{~kg}$ and examination revealed microcephaly (head circumference

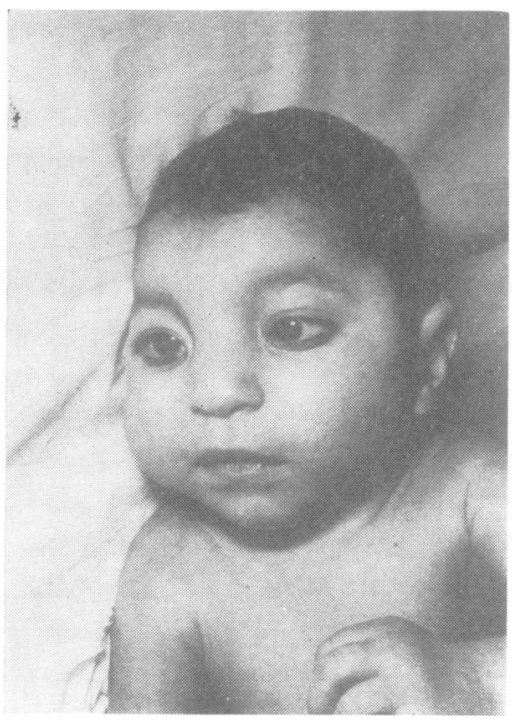

FIG 2 Case 2.

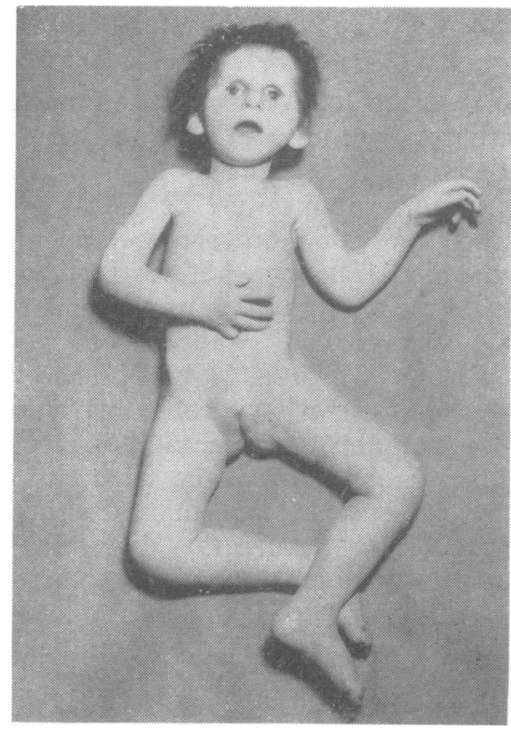

FIG 3 Case 3. 
$38.5 \mathrm{~cm},<3$ rd centile), microphthalmia, and cataracts. Investigations for rubella, cytomegalovirus, and toxoplasmosis were negative. Urine chromatography was normal and chromosome studies (G banded) showed a $46, \mathrm{XX}$ constitution. She had severe feeding difficulties, failed to thrive, and a developmental quotient on the Griffiths mental development scale was 24 at the age of 2 years. On examination at the age of 4 years, her weight was $7 \cdot 25 \mathrm{~kg}(<3$ rd centile), length $74 \mathrm{~cm}(<3$ rd centile), and head circumference $40 \mathrm{~cm}$ ( $<3 \mathrm{rd}$ centile). Her eyes were small and deep set and cataracts were present (fig 3). The ears were large, the nasal bridge was prominent, and the upper lip overhung the lower lip. The teeth were small and brittle. There was marked camptodactyly and a thoracic kyphosis was present.

She died at the age of $4 \frac{1}{2}$ years from pneumonia and acute cardiac failure. Permission for necropsy was not granted.

\section{Discussion}

Infants presenting with microcephaly, cataracts, and joint contractures with associated anomalies appear to fall into three groups (table).
(1) Those infants with relatively normal birthweight but with progressive postnatal growth deficiency and progressive pathology of the central nervous system, consisting of depletion of subcortical white matter and myelin, compatible with leucodystrophy. Examples of these patients include the original patients described as having the COFS syndrome by Pena and Shokeir, ${ }^{1}$ some of whom were later reinvestigated, ${ }^{2}$ the patients described by Lowry et al, ${ }^{3}$ (the necropsy on one of those patients was reported by Dolman and Wright ${ }^{14}$ ), and those described by Scott-Emuakpor et al. 4 These infants tend to have characteristic facial features consisting of microcephaly, microphthalmia, blepharophimosis, cataracts, prominent root of the nose, upper lip overhanging the lower, micrognathia, and large ear pinnas. Musculoskeletal abnormalities include camptodactyly and flexion contractures, dislocated hips with shallow acetabular angles, coxa valga, rocker-bottom feet, and a longitudinal groove on the soles. Pena et $^{2} \mathbf{l}^{2}$ suggested that the postnatal growth failure and cachexia were evidence of a primary growth deficiency. In addition to the progressive neurological pathology, some members of this group have

TABLE Comparison of present cases with reported cases of Neu Laxova and COFS syndromes

\begin{tabular}{|c|c|c|c|c|c|c|}
\hline Features & Case 1 & Case 2 & Case 3 & Neu-Laxova & $\begin{array}{l}\text { COFS } \\
\text { (early death) }\end{array}$ & $\begin{array}{l}\text { COFS } \\
\text { (classical) }\end{array}$ \\
\hline \multicolumn{7}{|l|}{ General } \\
\hline Age at death \pm SD & $3 \mathrm{~h}$ & $5 \mathrm{yr}$ & $4 \mathrm{yr}$ & $*$ & $\begin{array}{l}8 \mathrm{~d} \\
\pm 9 \cdot 5\end{array}$ & $\begin{array}{l}49 \mathrm{mth} \\
\pm 53\end{array}$ \\
\hline Failure to thrive & + & + & + & NA & $5 / 5$ & $17 / 17$ \\
\hline \multicolumn{7}{|l|}{ Head and neck } \\
\hline Microcephaly & + & + & + & $8 / 9$ & $4 / 4$ & $16 / 17$ \\
\hline Sloping forehead & + & + & - & $6 / 6$ & $4 / 5$ & $?$ \\
\hline Prominent root of nose & + & + & + & $1 / 7$ & $5 / 5$ & $8 / 8$ \\
\hline Flat nose and nasal bridge & - & - & - & $6 / 7$ & $0 / 5$ & $0 / 8$ \\
\hline Large ears & + & - & + & $2 / 3$ & $4 / 5$ & $9 / 9$ \\
\hline Micrognathia & + & - & - & $3 / 6$ & $3 / 5$ & $8 / 9$ \\
\hline Microphthalmia & + & - & + & $2 / 7$ & $3 / 4$ & $11 / 11$ \\
\hline Cataracts & + & + & + & $1 / 7$ & $3 / 4$ & $11 / 15$ \\
\hline Short neck & + & + & - & $6 / 6$ & $2 / 4$ & $0 / 10$ \\
\hline Kyphosis & - & + & + & $0 / 7$ & $2 / 5$ & $13 / 14$ \\
\hline Scoliosis & - & + & - & $0 / 7$ & $0 / 2$ & $13 / 14$ \\
\hline \multicolumn{7}{|l|}{ Extremities } \\
\hline Camptodactyly/finger deformity & + & + & + & $8 / 8$ & $5 / 5$ & $10 / 10$ \\
\hline Syndactyly & - & - & - & $4 / 6$ & $1 / 5$ & $0 / 9$ \\
\hline Flexion contractures & + & + & + & $8 / 8$ & $5 / 5$ & $14 / 16$ \\
\hline Rocker-bottom feet & + & - & - & $6 / 6$ & $3 / 5$ & $7 / 12$ \\
\hline \multicolumn{7}{|l|}{ Skin } \\
\hline Ichthyosis/collodion skin & + & - & - & $5 / 7$ & $0 / 5$ & $0 / 14$ \\
\hline Oedema of subcutis & + & - & - & $7 / 8$ & $0 / 5$ & $0 / 14$ \\
\hline CNS & & & & & & \\
\hline \multicolumn{7}{|l|}{ Hypoplasia or agenesis of the } \\
\hline corpus callosum & $?$ & $?$ & $?$ & $2 / 5$ & $2 / 3$ & $3 / 7$ \\
\hline Cerebellar hypoplasia & $?$ & $?$ & $?$ & $4 / 5$ & $1 / 3$ & $3 / 7$ \\
\hline Intracranial calcification & $?$ & $?$ & $?$ & $1 / 5$ & $0 / 3$ & $2 / 7$ \\
\hline
\end{tabular}

*Only one live born case (Neu et $a l^{9}$ ) died at 49 days. 
also shown cerebellar hypoplasia and agenesis of the corpus callosum. ${ }^{414}$ The average age at death is 4 years.

(2) Those infants described as being cases of the COFS syndrome who have died within the first few weeks of life. These infants in general have a low birthweight but show the facial and musculoskeletal features of the COFS syndrome. ${ }^{5-8}$ They can also have agenesis of the corpus callosum with cerebellar hypoplasia. ${ }^{6}$ Major visceral abnormalities are common. These include horseshoe kidney or renal agenesis, absence of the hemidiaphragm, malrotation of the colon, ${ }^{7}$ hypoplasia of the spleen and kidneys, ${ }^{6}$ and multiple foci of calcification in the heart and kidneys. ${ }^{8}$

(3) Those infants manifesting a highly lethal syndrome consisting of severe intrauterine growth retardation and often bizarre facial features with slanted forehead, retracted or absent eyelids, flattened nose, micrognathia, and low set ears. Major malformations of the brain have been reported including lissencephaly, complete or partial agenesis of the corpus callosum, and hypoplasia of the cerebellum. Some cases have ichthyosis or yellow, shiny, desquamating skin and oedema of the subcutis. In all, nine cases have been described. ${ }^{9-12}$ Lazjuk et al ${ }^{11}$ reviewed all the reported cases and suggested the title of the Neu-Laxova syndrome.

Following the initial reports of the COFS and Neu-Laxova syndromes some authors considered them to be the same entity. ${ }^{713}$ However, Pena et al, ${ }^{2}$ in their follow-up report, suggested that only those patients who had a relatively normal birthweight, no major visceral malformations, and who presented with progressive failure to thrive and progressive neurological pathology should be considered to have the COFS syndrome. They considered the patients described by Lurie $e t a l^{6}$ and Preus $e t a l^{7}$ to have a separate disorder. Presumably, by these criteria, they would also exclude the case described by Surana et al. ${ }^{8}$ Nevertheless, there is considerable similarity between the three groups (table). In addition to the common features of microcephaly, cataracts, contractures, and failure to thrive, subjects from each group have been found to have major central nervous system malformations consisting of agenesis or hypoplasia of the corpus callosum and hypoplasia of the cerebellum. Intracranial calcification has also been a common feature.

The grotesque facial features sometimes manifested in the Neu-Laxova syndrome, together with the syndactyly of hands and feet, severe oedema, and ichthyosis or yellow scaly skin seem to be peculiar to patients with this particular condition; however, no one feature serves to distinguish this syndrome completely. For example, the infants described by Taybi and Linden ${ }^{15}$ (pictures of one of whom appear in Holmes et $^{a^{16}}$ ), who presented with low birthweight, microcephaly, sloping forehead, flat bridge of the nose, bulging eyes, lissencephaly, agenesis of the corpus callosum, and skeletal dysplasia, share many features common to the NeuLaxova syndrome and to those infants described as having the COFS syndrome who died at an early age, especially the infant described by Surana et al. ${ }^{8}$

We consider our case 1 to be an example of the Neu-Laxova syndrome, phenotypically resembling case 3 of Neu et al, ${ }^{9}$ who came from a sibship where the other two affected infants were phenotypically similar to the cases reported by Laxova et al. ${ }^{10}$ However, there are considerable similarities between this patient of ours and those patients described as having the COFS syndrome who have died within the first few weeks of life. Our cases 2 and 3 appear to be like the COFS syndrome patients originally described by Pena and Shokeir, ${ }^{1}$ having relatively normal birthweights and postnatal failure to thrive in addition to the eye and musculoskeletal abnormalities.

Both the Neu-Laxova syndrome and the COFS syndrome are thought to be transmitted in an autosomal recessive fashion. It remains to be seen whether they represent extreme manifestations of homozygosity for the same allele at one locus, multiple allelism, or homozygosity for abnormal alleles at different loci. The similarities between these syndromes suggest a common biochemical or pathological origin.

The authors are grateful to Dr I Kessel for referring patient 1 and to Dr G Katz for referring patient 2.

\section{References}

1 Pena SDJ, Shokeir MHK. Autosomal recessive cerebrooculo-facio-skeletal (COFS) syndrome. Clin Genet 1974; 5:285-93.

2 Pena SDJ, Evans J, Hunter AGW. COFS syndrome revisited. Birth Defects 1978;XIV, 6B:205-13.

3 Lowry RB, MacLean R, MacLean DM, Tischler B. S Cataracts, microcephaly, kyphosis and limited joint $N$ movement in two siblings. A new syndrome. $J$ Pediatr $1971 ; 79: 282-4$.

4 Scott-Emuakpor AB, Heffelfinger J, Higgins JV. A syndrome of microcephaly and cataracts in four siblings. Am J Dis Child 1977;131:167-9.

5 Preus M, Fraser FC. The cerebro-oculo-facio-skeletal \& syndrome. Clin Genet 1974;5:294-7.

- Lurie IW, Cherstvoy GI, Lazjuk MK, Usoer SS. Further $\square$ evidence for the autosomal-recessive inheritance of the COFS syndrome. Clin Genet 1976;10:343-6.

7 Preus M, Kaplan P, Kirkham TH. Renal anomalies and $\frac{\varrho}{\mathscr{T}}$ oligohydramnios in the cerebro-oculo-facio-skeletal syndrome. Am J Dis Child 1977;131:62-4. 
8 Surana RB, Fraga JR, Sinkford SM. The cerebro-oculofacio-skeletal syndrome. Clin Genet 1978;13:486-8.

9 Neu RL, Lytt IG, Nagyfy SF, King S. A lethal syndrome of microcephaly with multiple congenital anomalies in three siblings. Pediatrics 1971;47:610-2.

10 Laxova R, O'Hara PT, Timothy JAD. A further example of a lethal autosomal recessive condition in sibs. J Ment Defic Res 1972;16:139-43.

11 Lazjuk GI, Lurie IW, Ostrowskaja TI, et al. The NeuLaxova syndrome-a distinct entity. Am J Med Genet $1979 ; 3: 261-7$

12 Pov́yšilová V, Macek M, Salichová J, Seemanová E. Letálni Syndrom mnohočetnych malformaci u třxi sourosencú. Cesk Pediatr 1976;31:190-4.
13 Temtamy SA, McKusick, VA. The genetics of hand malformations. New York: Liss, 1978:465.

14 Dolman CL, Wright VJ. Necropsy of original case of Lowry's syndrome. J Med Genet 1978;15:227-9.

15 Taybi H, Linden D. Congenital familial dwarfism with cephaloskeletal dysplasia. Radiology 1967;89:275-81.

16 Holmes LB, Moser HW, Halldorsson S, Maik MS, Pant SS, Matzilevich B. Mental retardation. New York: MacMillan, 1972:318-9.

Requests for reprints to Dr R M Winter, Division of Inherited Metabolic Diseases, Clinical Research Centre, Watford Road, Harrow, Middlesex HA1 3UJ. 